\title{
Solid pseudopapillary neoplasm of the pancreas: a case report
}

\author{
Corresponding author: \\ Elżbieta Ostańska, Medical Faculty, \\ University of Rzeszow, Rzeszow, \\ Poland, \\ e-mail: elaostanska@gmail.com
}

Medical Research Journal 2020;

Volume 5, Number 1, 50-54

10.5603/MRJ.a2020.0004

Copyright (C) 2020 Via Medica

ISSN 2451-2591

\begin{abstract}
This paper presents a case report of a solid pseudopapillary neoplasm (SPN) of the pancreas, a discussion on the clinical-pathological, histopathological, and immunohistochemical picture, and a review of the literature regarding the occurrence of this type of cancer. The case of a 61-year-old woman with the presence of a lithium-cystic lesion of the body and tail of the pancreas was initially assessed by MRI as a pathological mass with the presence of abscesses. Double biopsy under EUS control was non-diagnostic. The patient underwent surgery to remove the body and tail of the pancreas together with the tumour and spleen.

Tumour size $15 \times 10 \times 8 \mathrm{~cm}$ lithium-cystic, grey-brown, with the presence of numerous calcifications and bone metaplasia, and stones in the pancreatic duct. In the histopathological picture, solid woven with the presence of pseudodimplants and pseudocystic areas with haemorrhages. Positive tests for NSE, vimentin, PR, CD56, and cyclin D1 were obtained in immunohistochemical $(\mathrm{IHC})$ tests. The patient was discharged from the hospital in good general condition and is under gastroenterological control.

SPN is a rare cancer with low malignancy. The tumour most often occurs in teenagers or young women. Initially, it runs without ailments, until it is large. Then there is pain, nausea, and fever. The histopathological and cytological picture is suggestive, but it should be supported by research. SPN should be differentiated with neuroendocrine tumours (NENs) and acinar cancer and pancreatoblasoma. SPN generally has a good prognosis. Local relapses and distant metastases are rare.

Key words: pancreas, SPN, EUS, MRI, IHC
\end{abstract}

Med Res J 2020; 5 (1): 50-54

\section{Introduction}

The classification of pancreatic tumours is based on the type of cell differentiation line, e.g. ductal, acinar, neuroendocrine, etc. [1] SPN is a pancreatic cancer in which there is no differentiation into a specific cell line, and it is considered an undefined tumour histogenesis. [3] Most, because about $90 \%$ of pancreatic cancers occurring in adults are ductile infiltrating cancers. Cystic and intracystic tumours constitute about 4-5\%, neuroendocrine tumours about 3-4\%, acinar and other cancers up to $3 \%$, and SPN 0.9-2.7\% [1]. The introduction of imaging tests has increased the detection of small solid pancreatic tumours and cystic. Like other pancreatic cancers in the early stages of hyperplasia is an incidental find. Symptoms are non-specific; usually discomfort or nausea. Tumour haemorrhage after injury can give a sign of acute abdomen. All cancerous markers are normal. There are also no endocrine disorders. $90 \%$ of SPN occur in teenagers and young women - the average age is 28 years. This cancer is rare in men. Other acceptable names for SPN include: solid-pseudopapillary tumour, solid-cystic tumour, papillary cystic tumour, solid and papillary epithelial neoplasm, and Frantz tumour [1].

\section{Case report}

A 61-year-old patient was admitted to the Gastroenterology Clinic because of abdominal pain increasing for three months, loss of appetite, and weight loss of $8 \mathrm{~kg}$ in two months, as well as low-grade fever. In the abdominal ultrasound performed, a hypoechoic area of approximately $3.5 \mathrm{~cm}$ in diameter was found. CT scan revealed a lithium-cystic lesion within the body and tail of the pancreas up to $14 \mathrm{~cm}$ in diameter. The performed laboratory tests revealed anaemia $\left(E 3.98 \times 10^{\wedge} 6 / \mathrm{uL}\right.$, Hb 10.8 g/dL, Fe 22 ug/dl, TIBC 194 ug/dl, hyperuricemia during treatment, and CRP $17.0 \mathrm{mg} / \mathrm{dl}$. Other results were within the norms. Comorbidities included: chronic pancreatitis, gout, epilepsy, condition after surgical 


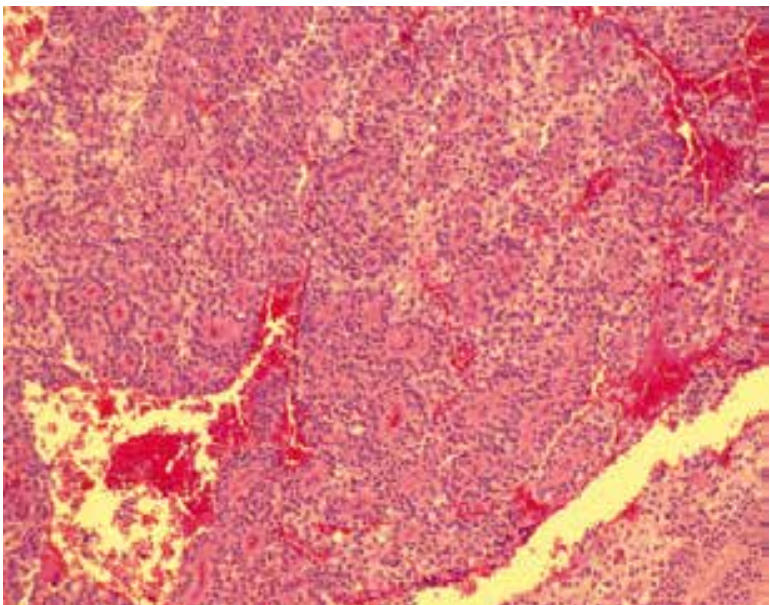

Figure 1. SPN solid weaving $10 \times$

treatment of meningioma in 2013. The family history of malignancies included: breast, stomach, and lung in parents, grandparents, and siblings. During the stay, two endosonographic examinations were performed, during which material for cytological examination was collected using PCl. The material proved to be barely diagnostic, and no proliferative change was found. Due to persistent elevated inflammatory markers and abdominal pain, an MRI examination of the pancreas was performed. MRI showed a pathological suppurative mass up to $15 \mathrm{~cm}$ in diameter. There were no metastases to lymph nodes or adjacent organs. The patient was qualified for surgery. The course of surgery was without complications. The body and tail of the pancreas with the tumour, spleen, and peri-lymph nodes were removed. Macroscopically, a cross-sectioned $15 \times 10 \times 8 \mathrm{~cm}$ tumour with fragments of pancreatic parenchyma and spleen was seen in sections. A greyish-red tumour with solid fields and cysts as well as numerous calcifications and bone foci was observed.

The remaining pancreas and spleen tissue and lymph nodes remained unchanged. In the microscopic image, the SPN depicted the structures of lite (Fig. 1), pseudocystic (Fig. 2), and pseudopapillary (Fig. 3-5). The solid and pseudocystic part was composed of monomorphic cells with eosinophilic or clear cytoplasm with vacuoles, nuclei with small nucleoli, and evenly distributed chromatin. Mitosis was sporadic. The cells were characterised by poor cohesion. The cells entwined the glazing and myxoid stroma. Bone elements (Fig. 4), calcifications (Fig. 5), histiocytes, and multinucleated giant cells were seen. Part of the weaving comprised abscesses and necrotic lesions. The tumour was well delimited from pancreatic parenchyma. There was no vascular invasion or nerve invasion. The tumour weaving gave positive IHC for cyclin D1, CD56, CD10, PR, vimentin, and NSE (Fig. 6-13).

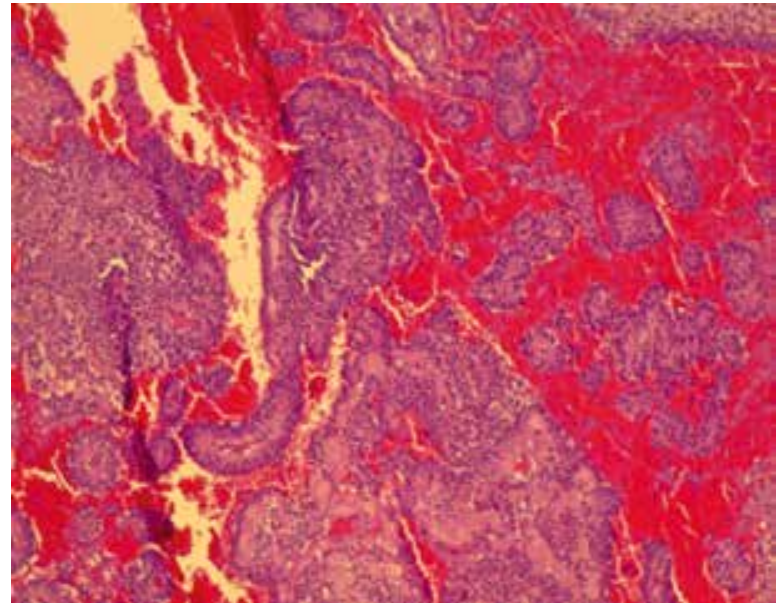

Figure 2. SPN haemorrhages and pseudocysts $10 \times$

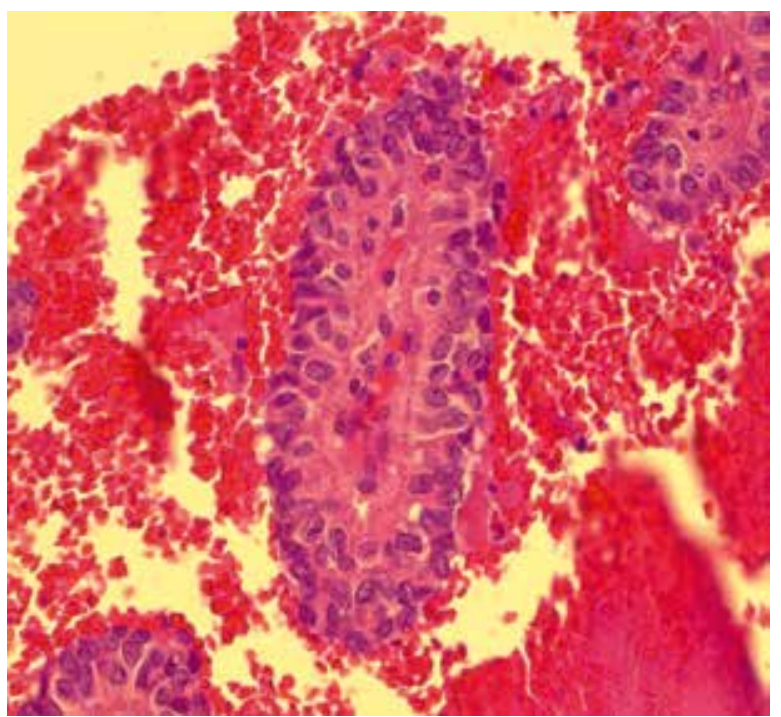

Figure 3. SPN calcified necrotic masses

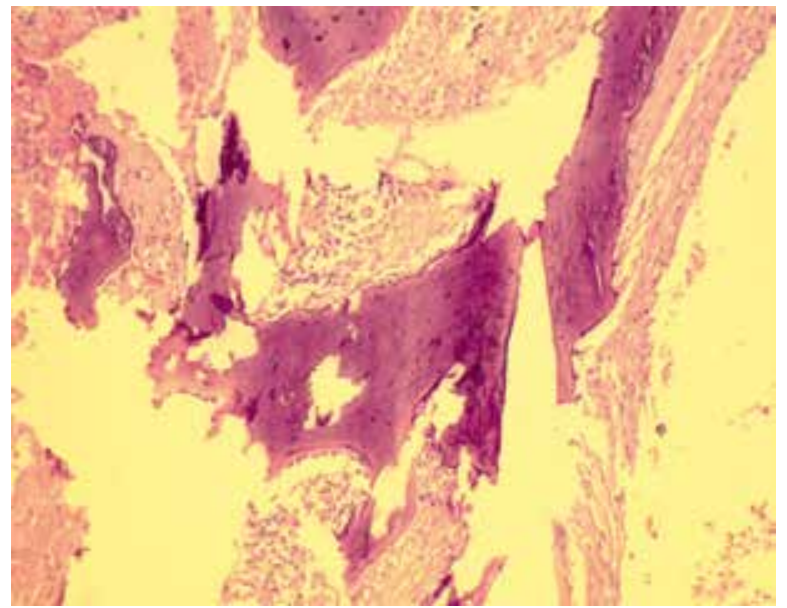

Figure 4. SPN bone elements $10 \times$ 


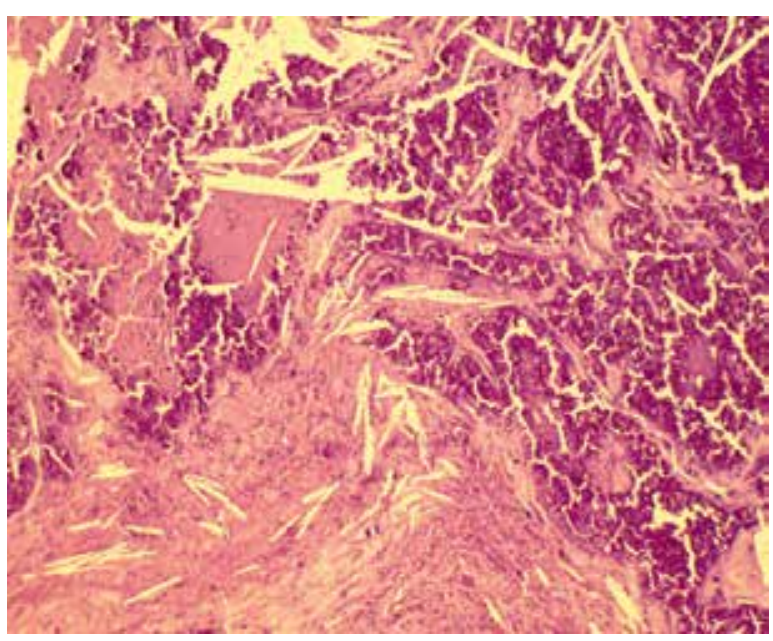

Figure 5. SPN pseudo wart $40 \times$

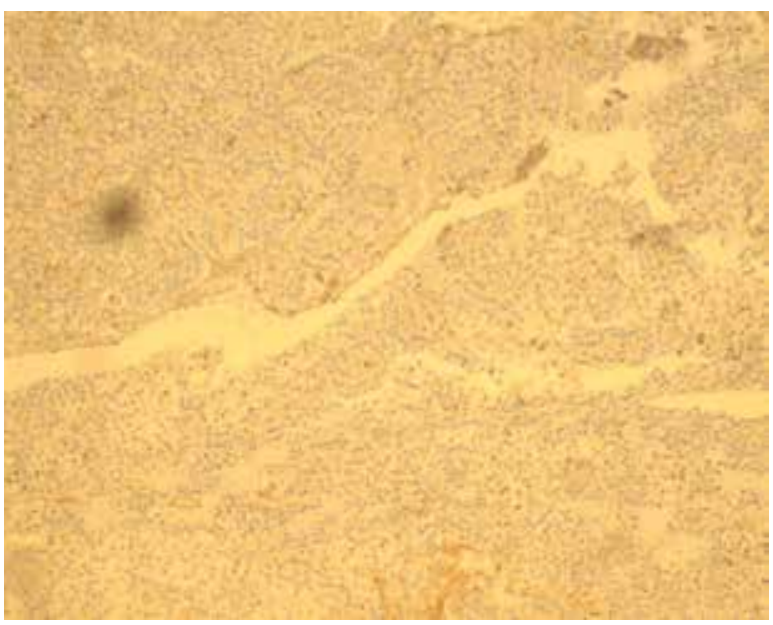

Figure 7. SPN CD $11710 \times$

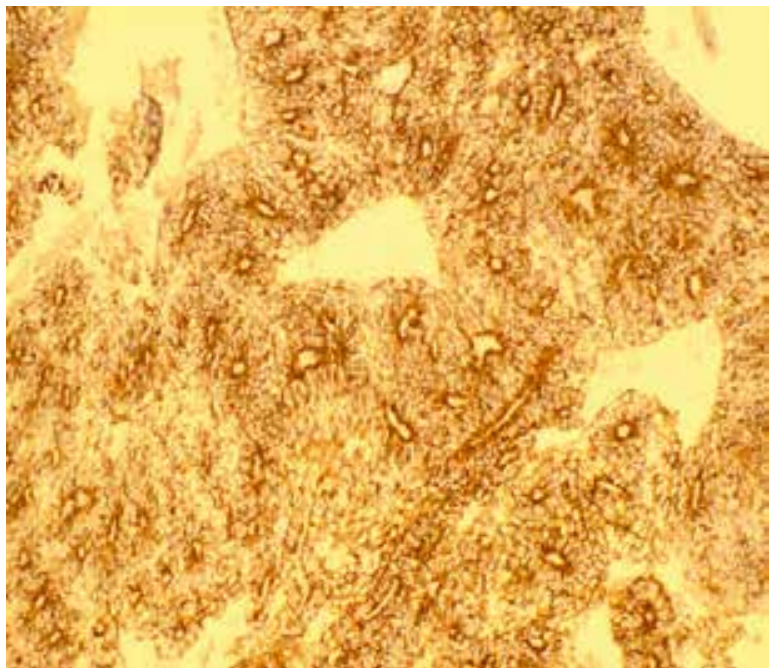

Figure 9. SPN CD $5610 \times$

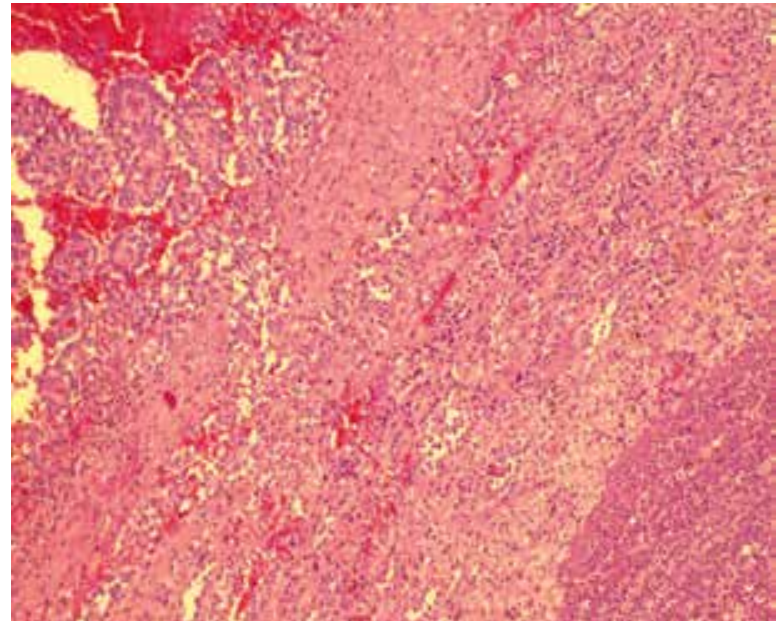

Figure 6. SPN necrotising lesions $10 \times$

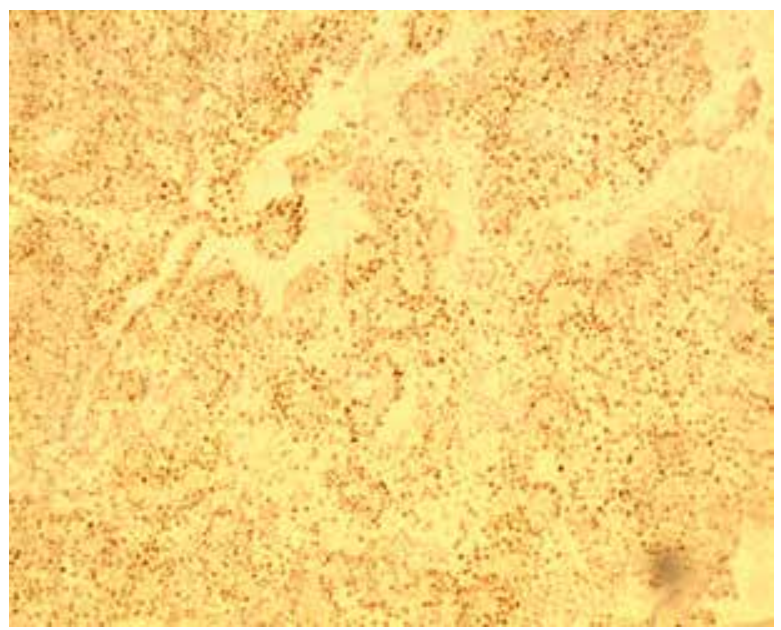

Figure 8. SPN Cyclic D1 10x

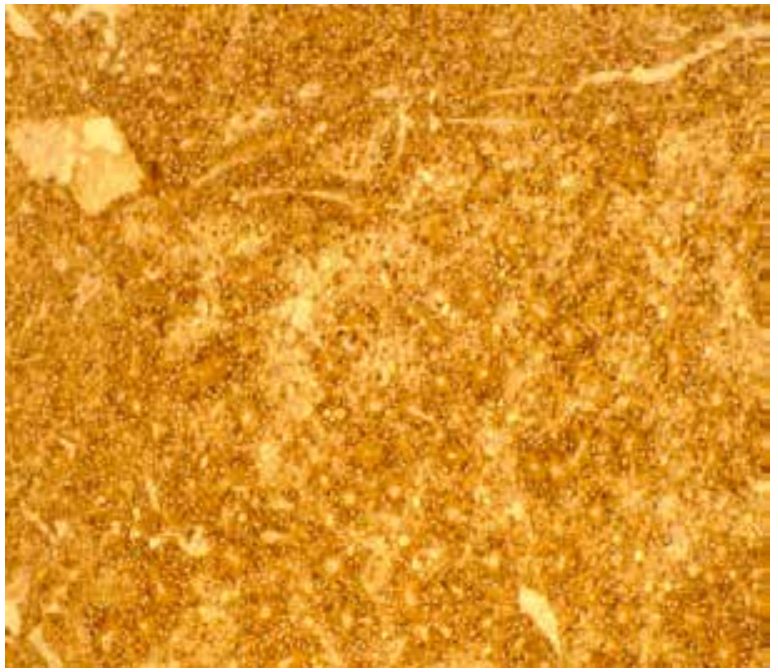

Figure 10. SPN CD $1010 \times$ 


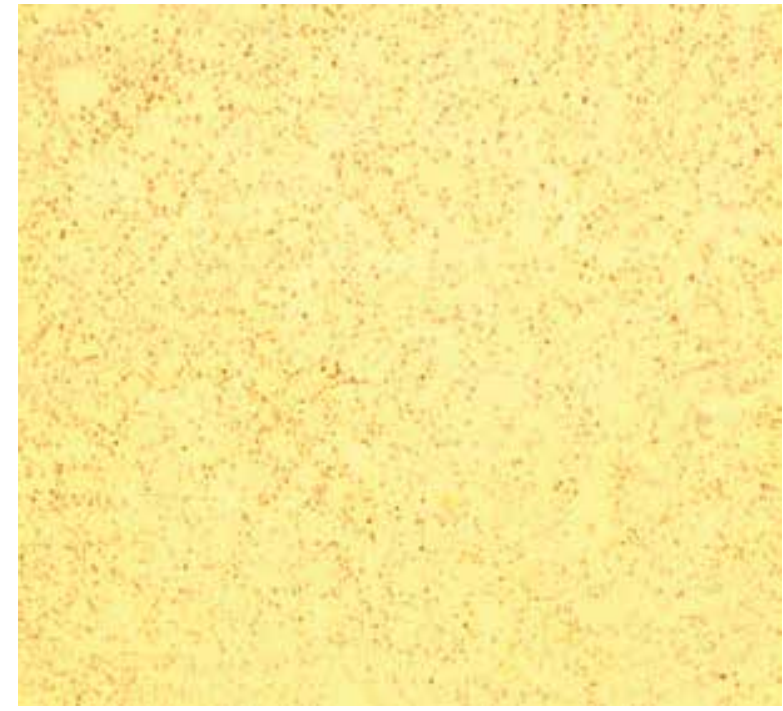

Figure 11. SPN PR 10x

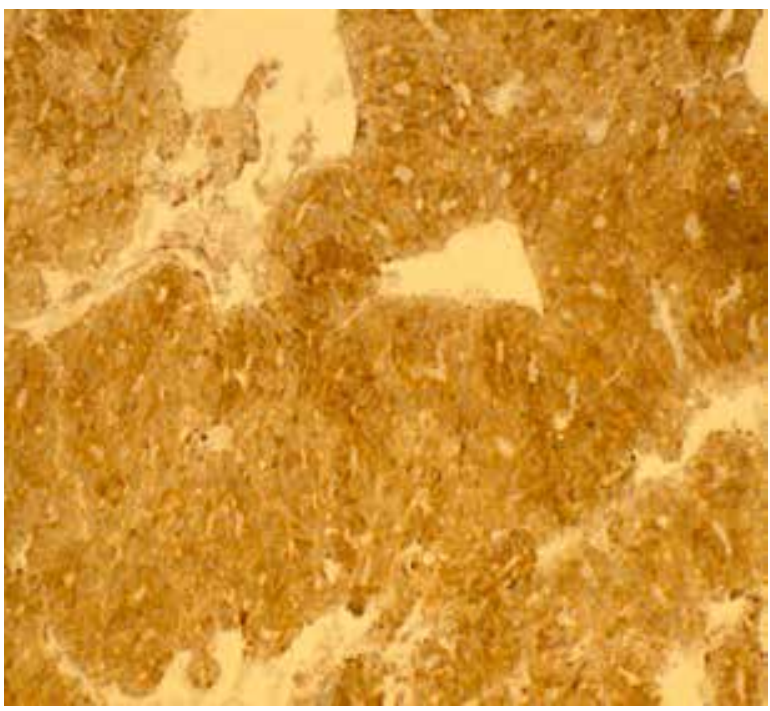

Figure 13. SPN NSE $10 \times$

The tumour was removed entirely with a healthy tissue margin. Lymph nodes and spleen were without tumour invasion. The following diagnosis was made: solid pseudopapillary neoplasm of the pancreas. pT2N0

Sixteen days after the surgery, the patient was discharged home in good condition. Due to the histopathological diagnosis of pancreatic cancer, the patient remains under the control of an oncologist.

\section{Discussion}

Better imaging methods allow detection of pancreatic tumours in a stage of low advancement, when their

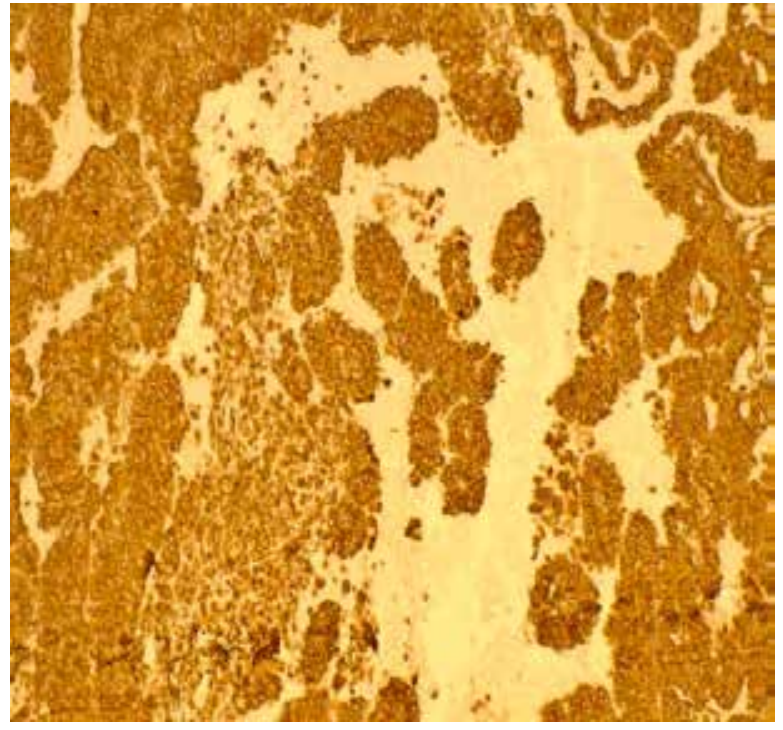

Figure 12. SPN Vimentin $10 \times$

size is $2-3 \mathrm{~cm}$. Such small pancreatic tumours can be removed by laparoscopic method [2-12].

Solid pseudopapillary neoplasm (SPN) of the pancreas, also called solid and cystic pancreatic neoplasm (SCPN) or Frantz's tumour, is a form of pancreatic cancer of unknown aetiopathogenesis.

It is a cancer of the pancreatic exocrine portion, and although it can occur at different ages, it

mainly develops in adolescents and women between 20 and 30 years of age. It is very rare in men [5]. A relationship with gender and age suggests a hormonal effect on tumour development, but such disorders have not yet been reported in its course. The tumour development is affected by the CTNNB1 somatic mutation (B-catenin coding site). CTNNB1 somatic mutation on exon 3 is the only known mutation in SPN to date. Like most tumours, when they are small, they are detected incidentally in imaging (USG, MRI, CT) [13-18]. Large tumours cause abdominal pain, abdominal discomfort, low-grade fever weight loss, and anaemia, and haemorrhage to the tumour may present a symptom of acute abdomen. The cytological picture of cell smears obtained by thin-needle biopsy via endoscopic ultrasound fine-needle aspiration allows for precise diagnosis of SPN [9]. Typically, the cytological picture contains numerous cohesive, non-coherent, small monomorphic tumour cells lining thin-walled vessels. Testicles with evenly distributed chromatin, a small nucleolus, sometimes with a convex, bent nuclear membrane. Sometimes there are bizarre testicles. Similarly, to the histopathological picture, the cells have eosinophilic or clear cytoplasm. Sometimes high-grade foci with pleomorphic cells and numerous mitoses are present within the tumour, which indicates transformation into a highly aggressive tumour. The tumour may directly infiltrate the 
duodenum, stomach, spleen, or portal vein. Sometimes there are hyaline globules that in ultrastructural image contain zymogen grains.

\section{Conclusions}

Solid pseudopapillary pancreatic neoplasm is a rare cancer of the pancreas. The cancer occurs in patients of a certain age and predominantly in females. The histopathological picture of the tumour and cytology are characteristic of the formation of solid fields, pseudopapillary and pseudocystic cysts, with the presence of inflammatory exudate, calcification, and multinucleated giant cells. Immunohistochemistry in the form of a reaction panel constitutes a complementary element of diagnostics. Currently, SPN is classified as a low-grade malignancy. The prognosis after complete tumour resection, even in the case of metastases and recurrences, is very good for young patients but slightly worse for older ones. Aneuploid SPNs are promising worse than diploid. Cancer detection at an early stage of development during research imaging may suggest a simple cyst or inflammatory lesions, createing the possibility of $100 \%$ cure with less invasive laparoscopic surgery.

\section{Acknowledgments}

Dorota Bartusik-Aebisher acknowledges support from the National Center of Science NCN (New drug delivery systems-MRI study, Grant OPUS-13 number 2017/25/B/ST4/02481).

\section{References}

1. Digestive System Tumors WHO Classification of Tumours 5th edition IARC 2019

2. Liang B, Chen Y, Li M, et al. Total laparoscopic duodenum-preserving pancreatic head resection for solid pseudopaillary neoplasm of pancreas: A case report. Medicine (Baltimore). 2019; 98(21) e15823, doi: 10.1097/MD.0000000000015823, indexed in Pubmed 31124984

3. Calvani J, Lopez P, Sarnacki S, et al. Solid pseudopapillary neoplasms of the pancreas do not express major pancreatic markers in pediatric patients. Hum Pathol. 2019; 83: 29-35, doi: 10.1016/j. humpath.2018.08.010, indexed in Pubmed: 30130629.
4. Liang B, Chen Y, Li M, et al. Total laparoscopic central pancreatectomy with Roux-Y pancreaticojejunostomy for solid pseudopapillary neoplasm of pancreas: A case report. Medicine (Baltimore). 2019; 98(18): e15495, doi: 10.1097/MD.0000000000015495, indexed in Pubmed: 31045833

5. De Moura DT, Coronel M, Ribeiro IB, et al. The importance of endoscopic ultrasound fine-needle aspiration in the diagnosis of solid pseudopapillary tumor of the pancreas: two case reports. J Med Case Rep. 2018; 12(1): 107, doi: 10.1186/s13256-018-1585-3, indexed in Pubmed: 29695287.

6. Gouta EL, Khalfallah M, Jerraya $\mathrm{H}$, et al. Pseudo papillary and solid tumor of the pancreas: a rare tumor and a difficult diagnosis. Tunis Med. 2017; 95(7): 229-232, indexed in Pubmed: 29694655.

7. McCluney S, Wijesuriya N, Sheshappanavar V, et al. Solid pseudopapillary tumour of the pancreas: clinicopathological analysis. ANZ J Surg. 2018; 88(9): 891-895, doi: 10.1111/ans.14362, indexed in Pubmed: 29316119.

8. Jung MJ, Kim HK, Choi SY, et al. Solid pseudopapillary neoplasm of the pancreas with liver metastasis initially misinterpreted as benign haemorrhagic cyst. Malays J Pathol. 2017; 39(3): 327-330, indexed in Pubmed: 29279599.

9. Rai S, Prabhu S, Rai S, et al. Image Findings of Solid Pseudopapillary Neoplasms of the Pancreas on Multiphasic Multidetector CT Scan-A Single Institute Experience from Southern India. J Clin Diagn Res. 2017; 11(9): TC01-TC05, doi: 10.7860/JCDR/2017/24190.10530, indexed in Pubmed: 29207802

10. Song He, Dong M, Zhou J, et al. Solid Pseudopapillary Neoplasm of the Pancreas: Clinicopathologic Feature, Risk Factors of Malignancy, and Survival Analysis of 53 Cases from a Single Center. Biomed Res Int. 2017; 2017: 5465261, doi: 10.1155/2017/5465261, indexed in Pubmed: 29094047.

11. Zhang $\mathrm{Y}, \mathrm{Han} \mathrm{Xu}, \mathrm{Wu} \mathrm{H}$, et al. Bioinformatics analysis of transcription profiling of solid pseudopapillary neoplasm of the pancreas. Mol Med Rep. 2017; 16(2): 1635-1642, doi: 10.3892/mmr.2017.6800, indexed in Pubmed: 28627654

12. Lima CA, Silva A, Alves C, et al. Solid pseudopapillary tumor of the pancreas: Clinical features, diagnosis and treatment. Rev Assoc Med Bras (1992). 2017; 63(3): 219-223, doi: 10.1590/1806-9282.63.03.219, indexed in Pubmed: 28489126.

13. Beltrame V, Pozza G, Dalla Bona E, et al. Solid-Pseudopapillary Tumor of the Pancreas: A Single Center Experience. Gastroenterol Res Pract. 2016; 2016: 4289736, doi: 10.1155/2016/4289736, indexed in Pubmed: 28119738

14. Hatano $Y$, Kawashima K, Iwashita T, et al. A Solid Pseudopapillary Neoplasm of the Pancreas Associated With IgG4-Related Pancreatitis: A Case Report. Int J Surg Pathol. 2017; 25(3): 271-275, doi: 10.1177/1066896916677289, indexed in Pubmed: 28107092.

15. Anil G, Zhang J, Al Hamar NE, et al. Solid pseudopapillary neoplasm of the pancreas: CT imaging features and radiologic-pathologic correlation. Diagn Interv Radiol. 2017; 23(2): 94-99, doi: 10.5152/dir.2016.16104, indexed in Pubmed: 28089954.

16. Zeytunlu M, Firat O, Nart D, et al. Solid and cystic papillary neoplasms of the pancreas: report of four cases. Turk J Gastroenterol. 2004; 15(3): 178-182, indexed in Pubmed: 15492918.

17. Pelosi G, lannucci A, Zamboni G, et al. Solid and cystic papillary neoplasm of the pancreas: a clinico-cytopathologic and immunocytochemical study of five new cases diagnosed by fine-needle aspiration cytology and a review of the literature. Diagn Cytopathol. 1995; 13(3): 233-246, doi: 10.1002/dc.2840130311, indexed in Pubmed: 8575283.

18. Rai S, Prabhu S, Rai S, et al. Image Findings of Solid Pseudopapillary Neoplasms of the Pancreas on Multiphasic Multidetector CT Scan-A Single Institute Experience from Southern India. J Clin Diagn Res. 2017: 11(9): TC01-TC05, doi: 10.7860/JCDR/2017/24190.10530, indexed in Pubmed: 29207802. 